\title{
Detecção do vírus herpes simples por reação em cadeia da polimerase em pacientes com ceratite herpética típica ou atípica
}

\author{
Molecular detection of herpes simplex virus by polymerase chain reaction \\ in patients with typical and atypical herpetic keratitis
}

\author{
Afonso Kamimura ${ }^{1}$ \\ Magali Ineko Takata ${ }^{2}$ \\ Ana Carolina Moraes Fernandes ${ }^{3}$ \\ João Paulo Neves ${ }^{4}$ \\ Marco Túlio Chater Viegas ${ }^{5}$ \\ Valquise Yumi Murata ${ }^{6}$ \\ Maurício Lacerda Nog'ueira ${ }^{7}$ \\ Gildásio Castello de Almeida Júnior ${ }^{8}$
}

\begin{tabular}{|l|}
\hline RESUMO \\
\hline Objetivo: Avaliação dos pacientes com o quadro clínico de ceratite \\
herpética $(\mathrm{CH})$ típicas e atípicas, pela reação em cadeia da polimerase \\
(PCR) correlacionando com o diagnóstico clínico. Métodos: Foi realizada \\
a PCR em 28 pacientes com ceratite herpética típica e atípica. Resultados: \\
A PCR foi positiva em 57,14\% $(\mathrm{n}=16)$ do total $(\mathrm{n}=28)$. Nos casos de CH \\
típica a positividade foi de 60,00\% $(\mathrm{n}=12)$ em 20 casos. Para CH epitelial \\
a positividade foi de 69,23\% $(\mathrm{n}=9)$, sendo $77,78 \%(\mathrm{n}=7)$ apenas para as \\
lesões epiteliais dendríticas. Os casos de CH atípica apresentaram po- \\
sitividade de 50\% (n=4) em oito casos. Conclusão: Quadro clínico típico \\
de CH teve boa correlação com o resultado positivo observado na PCR. \\
Entretanto, metade dos pacientes com o quadro de CH atípica apresentou \\
PCR positivo, portanto, o exame do PCR é teste importante para o auxílio \\
e diagnóstico da CH. No caso de CH estromal, foi demonstrado que a \\
técnica da PCR conseguiu identificar o vírus HSV. \\
\hline
\end{tabular}

Descritores: Ceratite; Ceratite herpética; Herpes simples; Reação em cadeia da polimerase; Córnea

\footnotetext{
Trabalho realizado na Faculdade de Medicina de São José do Rio Preto (SP) - Brasil.

${ }^{1}$ Acadêmico de Medicina da Faculdade de Medicina de São José do Rio Preto (SP) - Brasil.

${ }^{2}$ Acadêmica de Medicina da Faculdade de Medicina de São José do Rio Preto (SP) - Brasil.

Acadêmica de Medicina da Faculdade de Medicina de São José do Rio Preto (SP) - Brasil.

${ }^{4}$ Residente de Oftalmologia da Faculdade de Medicina de São José do Rio Preto (SP) - Brasil.

${ }^{5}$ Residente de Oftalmologia da Faculdade de Medicina de São José do Rio Preto (SP) - Brasil.

${ }^{6}$ Residente de Oftalmologia da Faculdade de Medicina de São José do Rio Preto (SP) - Brasil.

Doutor, Professor do Departamento de Doenças Dermatológicas Infecciosas e Parasitárias, Faculdade de Medicina de São José do Rio Preto (SP) - Brasil.

${ }^{8}$ Doutor, Médico do Departamento de Especialidades Cirúrgicas, Faculdade de Medicina de São José do Rio Preto (SP) - Brasil.

Endereço para correspondência: Afonso Kamimura. Rua Joaquim Manoel Pires, 65 - Apto. 22 - São José do Rio Preto (SP) CEP 15091-210

E-mail: afonsomed36@yahoo.com.br

Recebido para publicação em 29.08.2006

Última versão recebida em 24.06.2008

Aprovação em 23.10.2008
}

\section{INTRODUÇÃO}

A infecção pelo vírus do herpes simples (HSV) é cosmopolita. Estima-se que no mundo $60 \%-70 \%$ das crianças com cinco anos de idade e aproximadamente $90 \%$ dos adultos apresentam soropositividade para os antígenos do HSV-1. Destes apenas 20\%-30\% apresentam sinais clínicos da doença, e as manifestações oculares ocorrem em menos de $1 \%{ }^{(1-2)}$.

Atualmente, a ceratite herpética é a causa mais comum de ulceração da córnea e de cegueira infecciosa unilateral. Geralmente as lesões são unilaterais, e aproximadamente $5 \%$ dos casos são por lesões bilaterais e estão associados à atopia ${ }^{(1-2)}$.

Tradicionalmente, o diagnóstico da ceratite herpética é basicamente clínico, ocasionalmente necessitando da cultura viral, o exame laboratorial somente é necessário nos casos atípicos ou para estudos ${ }^{(3)}$.

A metodologia de PCR (Reação em cadeia da polimerase) tem como objetivo a amplificação exponencial de DNA. Desta forma é exatamente isto e apenas isto que ela detecta, ou seja, a presença ou ausência de DNA. Seja da forma competitiva, qualitativa ou mesmo por "real-time" (qualitativo e/ou quantitativo) o objetivo da reação é amplificar seqüências alvo de DNA. Em nosso trabalho a seqüência alvo é o gene TK de HSV. A amplificação de HSV 
neste tecido mostra a presença de DNA viral no tecido. Este DNA só pode ter origem na partícula viral ${ }^{(4-5)}$. Portanto, o PCR detecta a presença do DNA viral. Entretanto no caso de doença ocular externa a presença de DNA de HSV nem sempre significa a presença de infecção ativa, pois pode detectar partículas virais (vírus vivo ou morto) e antígenos virais, ou seja, pode ser positivo mesmo que não haja infecção ativa. $\mathrm{O}$ mesmo ocorre com o rt-PCR ("real time"-PCR), porém este exame avalia a existência ou não atividade viral pelo número de partículas encontradas. O PCR "competitivo" é o único que detecta se há infecção ativa (Recombinação do RNA com o DNA do vírus) ${ }^{(6-8)}$.

Por conseguinte à presença de DNA de citomegalovírus por PCR no sangue do paciente não significa necessariamente que a pessoa está tendo uma infecção ativa por citomegalovírus, pois linfócitos são um dos sítios de latência do mesmo. É importante ressaltar que esta diferenciação não depende apenas do tipo de PCR, mas sim da biologia do agente e do tecido utilizado. No caso de doença herpética cutânea, ocular e/ou de mucosa a detecção do DNA viral é um importante sinal da presença de partícula e/ou infecção ${ }^{(4-5)}$.

O objetivo deste estudo foi o de avaliar os casos de ceratite epitelial infecciosa, ceratite estromal imune pelo HSV, bem como os casos de ceratites atípicas suspeitas de infecção pelo HSV, pela PCR correlacionando com o diagnóstico clínico.

\section{MÉTODOS}

O estudo foi realizado no Ambulatório de Oftalmologia da Faculdade de Medicina de São José do Rio Preto (FAMERP) no período de junho de 2005 a maio de 2006, sendo realizado de acordo com a declaração de Helsinki ${ }^{(9)}$. Todos os pacientes foram informados e assinaram termo de consentimento, sendo o trabalho aprovado pelo comitê de ética em pesquisa (CEP) ${ }^{(10)}$ da FAMERP sob o protocolo número 0042.0.140.000-05.

\section{Caracterização da amostra e critério de inclusão}

Foram selecionados pacientes apresentando quadro clínico de ceratite herpética diagnosticada à biomicroscopia, segundo classificação de Holland e Schwartz ${ }^{(8)}$ e pacientes com ceratite atípica, com ou sem história prévia de doença herpética sistêmica ou ocular, primária ou recorrente, que não estavam em uso da terapia antiviral. Também foram selecionados pacientes submetidos à ceratoplastia penetrante com quadro de falência primária do enxerto ou rejeição do aloenxerto.

Holland e Schwartz ${ }^{(11)}$ classificaram as ceratites herpéticas da seguinte maneira:

A) Ceratite epitelial infecciosa - presença de vírus ativo, apresenta quatro formas de manifestação:

A.1) Vesículas - forma inicial, difícil diagnóstico.

A.2) Ceratite dendrítica - forma mais comum. Dendrito é geralmente central, pode ser único ou múltiplo e apresenta bulbo terminal nas ramificações.

A.3) Ceratite geográfica - extensão das ramificações do dendrito.
A.4) Ceratite marginal - semelhante ao dendrito, porém localiza-se na periferia da córnea.

B) Ceratopatia neurotrófica - úlceras rasas e arredondadas no epitélio, geralmente na região central, sem presença de vírus.

C) Ceratites estromais

C.1) Ceratite estromal imune - formação do complexo antígeno-anticorpo ocasionando inflamação estromal. Pode apresentar diversas formas, tais como edema estromal focal ou difuso, anel imunológico e neovascularização superficial ou profunda.

C.2) Ceratite necrotizante - inflamação estromal por ação direta do vírus. Apresenta infiltrado estromal denso e necrose tecidual.

D) Endotelite - inflamação endotelial, provavelmente de origem imunológica, resultando edema estromal e epitelial secundários. Apresenta três formas de manifestação.

D.1) Endotelite disciforme

D.2) Endotelite linear

D.3) Endotelite difusa

\section{Coleta da amostra}

Após o exame clínico e a assinatura do consentimento informado foi realizada a colheita da amostra mediante zaragatoa no olho acometido. Utilizou-se uma haste de plástico que tem a extremidade de algodão. Esta foi friccionada com movimento circular, delicado e firme, mantendo leve pressão sobre a córnea por alguns segundos. Depois, a haste foi quebrada, sendo a parte distal mergulhada no tubo de ensaio contendo $1 \mathrm{~mL}$ do meio para transporte viral.

Este meio consiste de meio DMEM (Dulbecco's Modified Eagle's Medium), contendo ampicilina, estreptomicina e fungizona. Após a coleta foi mantido em $4^{\circ} \mathrm{C}$ até o processamento da amostra.

\section{Processamento e armazenamento}

A amostra foi então levado ao Laboratório de Pesquisas em Virologia onde a alíquota foi estocada a $-80^{\circ} \mathrm{C}$.

\section{PCR - Reação em cadeia da polimerase}

A PCR foi realizada conforme descrito em Nogueira et al. ${ }^{(12-13)}$. O meio de transporte de vírus contendo o swab foi diluído 1/10 e aquecido a $99^{\circ} \mathrm{C}$ por 10 minutos. Alternativamente será feita a extração do DNA com Fenol/Clorofórmio segundo protocolo padrão.

Após a extração o DNA foi amplificado por meio da PCR utilizando iniciadores específicos para a região que codifica a timidina quinase viral. A reação de PCR contém: $2 \mathrm{mM}$ de $\mathrm{MgCl}$, dNTPs, $1 \%$ de glicerol, $1 \mathrm{U}$ de Taq polimerase (PROMEGA), 10pM de iniciadores HSV1TK3 5'TCAGTTAGCCTCCCCCATC e HSV1TK5 5' ATGGCTTCGTACCCCTGCC, tampão e DNA. Após a amplificação as amostras foram então dissolvidas em gel de agarose $1 \%$ e comparadas com o controle positivo (cultura de HSV-1). Controles negativos serão incluídos em cada reação. 


\section{Montagem do banco de dados}

Foi elaborado um banco de dados no programa Microsoft Excel $^{\circledR}$ com os pacientes que satisfizeram os critérios de inclusão e que assinaram o termo de consentimento livre e esclarecido. Foram avaliados: as queixas do paciente, o uso de medicamentos sistêmicos ou oculares, o olho acometido, e as principais características da lesão conforme o protocolo em anexo.

\section{RESULTADOS}

Dos 28 pacientes com amostra coletada, 60,71\% $(n=17)$ eram do sexo masculino e 39,29\% (n=11), feminino. A média de idade para ambos os sexos foi de 51,59 anos $(\mathrm{DP}=16,75)$. O olho direito foi o mais acometido $57,14 \%(\mathrm{n}=16)$ dos casos, $37,51 \%(\mathrm{n}=10)$ dos pacientes se queixaram do olho esquerdo e apenas $7,14 \%(n=2)$ apresentaram alteração em ambos.

A positividade para o HSV foi detectada pelo PCR em 15 dos 28 olhos dos pacientes. A técnica da PCR foi positiva em 60,00\% ( $\mathrm{n}=12$ ) dos pacientes com o quadro clínico típico de ceratite herpética num total de 20 pacientes. No grupo com o quadro clínico atípico de $\mathrm{CH}$ a PCR foi positiva em $50 \%(\mathrm{n}=4)$ do total de casos $(\mathrm{n}=8)$.

No grupo da CH típica, as lesões epiteliais ponteadas, dendríticas ou ulcerativas (ceratite geográfica) apresentaram 69,23\% $(n=9)$ de positividade para a PCR de um total de 13 pacientes (Tabela 1). As lesões do tipo dendritos mostraram sensibilidade de 77,78\% (n=6) (Tabela 2). A CH estromal apresentou positividade de $42,86 \%(n=3)$ (Tabela 3 ).

\section{DISCUSS ÃO}

Vários métodos incluindo a cultura viral ${ }^{(14-19)}$, reação da cadeia da polimerase ${ }^{(19-25)}$, imuno-histoquímica ${ }^{(25-26)}$, e hibridização in situ ${ }^{(23)}$ têm sido usados para o diagnóstico do HSV tipo 1 em córneas humanas. O trabalho de El-Aal $\mathrm{AM}^{(3)}$ mostrou que a cultura do vírus herpes simples foi positiva em 10 (20,8\%) de 48 casos suspeitos de ceratite herpética epitelial dendrítica com infiltrado subendotelial. A sensibilidade da PCR foi de $70 \%$ e especificidade de $71,4 \%$ e a imunofluorescência apresentou sensibilidade de $80 \%$ com valor preditivo negativo de $81,8 \%$. A sensibilidade da PCR, nas ceratites herpéticas epiteliais do tipo dendrítica com infiltrado subepitelial, realizada no estudo de Farhatullah et al. ${ }^{(27)}$ foi de $81,2 \%$. Em outro estudo, o resultado da sensibilidade da PCR para detectar a $\mathrm{CH}$ epitelial típica foi de $77,0 \%{ }^{(28)}$. Em nosso estudo, os pacientes com o quadro clínico de $\mathrm{CH}$ típica, 60,0\% apresentaram positividade para o PCR, mas quando limitamos a análise apenas para a lesão epitelial (ponteadas, dendríticas ou geográficas) o resultado foi de $69,23 \%$ e de $77,78 \%$ quando restringimos apenas para lesões dendríticas clássicas. Uma explicação para o fato é que a lesão epitelial dendrítica concentre maior quantidade de vírus vivo para a realização do swab e PCR.

\begin{tabular}{|lcc|}
\hline \multicolumn{3}{|c|}{ Tabela 1. Ceratite herpética epitelial típica } \\
\hline $\mathbf{n}$ ㅇ & PCR & (\%) \\
8 & Positivos & 69,23 \\
4 & Negativos & 30,77 \\
\hline $\mathrm{n}^{0}=$ número de pacientes; $P C R=$ & reação em cadeia da polimerase \\
\hline
\end{tabular}

\begin{tabular}{|c|c|c|}
\hline $\mathrm{n}$ 은 & PCR & $(\%)$ \\
\hline 6 & Positivo & 77,78 \\
\hline 2 & Negativo & 22,22 \\
\hline
\end{tabular}

\begin{tabular}{|c|c|c|}
\hline $\mathrm{n}^{\circ}$ & PCR & (\%) \\
\hline 3 & Positivo & 42,86 \\
\hline 4 & Negativo & 57,14 \\
\hline
\end{tabular}

Para as $\mathrm{CH}$ estromais, a positividade foi de $42,68 \%$ no trabalho feito por Martinez et al. ${ }^{(28)}$, a sensibilidade foi de $20 \%$ para $\mathrm{CH}$ estromais.

Nesse estudo observa-se uma boa correlação entre a positividade do PCR e o quadro clínico, quando este se limita mais para a lesão clássica da $\mathrm{CH}$ (lesões do tipo dendríticas). O estudo de Koizumi et al. ${ }^{(29)}$ mostrou que a sensibilidade para o quadro atípico foi de 50\%. Em nosso estudo, pacientes com o quadro de $\mathrm{CH}$ atípica, a positividade para o PCR foi de $50 \%$.

A metodologia por nós utilizada foi descrita em Nogueira, et al. ${ }^{(12,13)}$ é similar aos trabalhos citados. Existem pequenas diferenças na metodologia de extração de DNA, porém os resultados são similares.

Apesar dos resultados obtidos é importante salientar que esse estudo apresenta algumas limitações, como por exemplo, o pequeno número amostral, a não realização de culturas e não realização dos controles negativos e positivos. Mais estudos devem ser realizados para avaliar o papel do PCR no diagnóstico das ceratites herpéticas com quadro clínico típico e atípico.

\section{CONCLUSÃO}

A suspeita clínica diante de um quadro clínico típico de $\mathrm{CH}$ teve uma boa correlação com o resultado positivo observado na PCR. Entretanto, metade dos pacientes com o quadro de $\mathrm{CH}$ atípica apresentou PCR positivo, o que torna nesses casos, o exame do PCR um teste importante para o auxílio e diagnóstico da $\mathrm{CH}$. No caso de $\mathrm{CH}$ estromal, foi demonstrado que a técnica da PCR conseguiu identificar a partícula de DNA do vírus HSV. 


\section{ABSTRACT}

Purpose: To evaluate patients with clinically typical and atypical herpetic keratitis (HK) by means of polymerase chain reaction $(\mathrm{PCR})$ as compared with the clinical diagnosis. Methods: PCR in 28 patients with clinical symptoms of typical and atypical HK was performed. Results: PCR was positive in $57.14 \%(n=16)$ of the total cases $(n=28)$. The test was positive in $60.0 \%(n=12)$ of the 20 typical HK cases. For epithelial HK, the test was positive in $69.23 \%(\mathrm{n}=9)$, and $77.78 \%(\mathrm{n}=7$ ) only for dendritic injuries. Atypical HK presented a positive test in $50 \%(n=4)$ of eight cases. Conclusion: Clinical typical picture of HK had a good correlation with the positive result of PCR, mainly for epithelial injury of the dendritic type. However, $50 \%$ of the patients with atypical HK presented positive PCR. This result showed that PCR test can provide an effective HK diagnosis. In the stromal case of HK, PCR was a useful technique to identify HSV virus.

Keywords: Keratitis; Keratitis, herpetic; Herpes simplex; Polymerase chain reaction; Cornea

\section{REFERÊNCIAS}

1. Nogueira ML, Bonjardim CA, Ferreira PCP, Kroon EG. Herpesvírus. In: Oréfice F, organizador. Uveíte: clínica e cirúrgica. Rio de Janeiro: Cultura Médica; 2000. p.532-41.

2. Liesegang TJ. Herpes simplex virus epidemiology and ocular importance. Cornea. 2001;20(1):1-13.

3. El-Aal AM, El Sayed M, Mohammed E, Ahmed M, Fathy M. Evaluation of herpes simplex detection in corneal scrapings by three molecular methods. Curr Microbiol. 2006;52(5):379-82.

4. Kroon EG, Bonjardim CA, Ferreira PCP, Nogueira ML. PCR. In: Oréfice F, organizador. Uveíte: clínica e cirúrgica. Rio de Janeiro: Cultura Médica; 2000. p.276-82.

5. Nogueira ML, Bonjardim CA, Ferreira PCP, Kroon EG. Herpesvírus. In: Oréfice F, organizador. Uveíte: clínica e cirúrgica. Rio de Janeiro: Cultura Médica; 2000. p.532-41.

6. Babu JS, Kanangat S, Rouse BT. Limitations and modifications of quantitative polymerase chain reaction. Application to measurement of multiple mRNAs present in small amounts of sample RNA. J Immunol Methods. 1993;165(2): 207-16.

7. Thomas J, Rouse BT. Immunopathogenesis of herpetic ocular disease. Immunol Res.1997;16(4):375-86.

8. Daheshia M, Kuklin N, Kanangat S, Manickan E, Rouse BT. Suppression of ongoing ocular inflammatory disease by topical administration of plasmid DNA encoding IL-10. J Immunol. 1997;159(4):1945-52.

9. The World Medical Association. World Medical Association Declaration of Helsinki. Ethical Principles for Medical Research Involving Human Subjects. [Internet].France: WMA; c2003-2007. [cited 2007 Oct 26]. Available from: http://www.wma.net/e/policy/pdf/17c.pdf
10. Faculdade de Medicina de São José do Rio Preto. Comitê de Ética em Pesquisa [Internet]. [citado 2007 Out 26]. Disponível em: http://www.cep.famerp.br/

11. Holland EJ, Schwartz GS. Classification of herpes simplex virus keratitis Cornea. 1999;18(2):144-54.

12. Nogueira ML, Carvalho AF, Barbosa EF, Bonjardim CA, Ferreira PC, Kroon EG. Diagnosis of mucocutaneous herpetic infections by PCR without DNA extraction. Mem Inst Oswaldo Cruz. 1998;93(2):213-4.

13. Nogueira ML, Amorim JB, Oliveira JG, Bonjardim CA, Ferreira PC, Kroon EG. Comparison of virus isolation and various polymerase chain reaction methods in the diagnosis of mucocutaneous herpesvirus infection. Acta Virol. 2000;44(2):61-5.

14. Crouse CS, Pflugfelder SC, Pereira I, Cleary T, Rabinowitz S, Atherton SS. Detection of herpes viral genomes in normal and diseased corneal epithelium. Curr Eye Res. 1990;9(6):569-81.

15. Shimeld C, Tullo AB, Easty DL, Thomsitt J. Isolation of herpes simplex virus from the cornea in chronic stromal keratitis. Br J Ophthalmol. 1982;66(10):643-7.

16. Tullo AB, Easty DL, Shimeld C, Stirling PE, Darville JM. Isolation of herpes simplex virus from corneal discs of patients with chronic stromal keratitis. Trans Ophthalmol Soc U K. 1985;104(Pt 2):159-65.

17. Easty DL, Shimeld C, Claoue CM, Menage M. Herpes simplex virus isolation in chronic stromal keratitis: human and laboratory studies. Curr Eye Res. 1987; 6(1):69-74.

18. Coupes D, Klapper PE, Cleator GM, Bailey AS, Tullo AB. Herpesvirus simplex in chronic human stromal keratitis. Curr Eye Res. 1986;5(10):735-8.

19. Cook SD, Aitken DA, Loeffler KU, Brown SM. Herpes simplex virus in the cornea; an ultrastructural study on viral reactivation. Trans Ophthalmol Soc U K. 1986;105(Pt 6):634-41.

20. Kaye SB, Lynas C, Patterson A, Risk JM, McCarthy K, Hart CA. Evidence for herpes simplex viral latency in the human cornea. Br J Ophthalmol. 1991; 75(4):195-200. Comment in: Br J Ophthalmol. 1991;75(4):193-4.

21. Crouse CA, Pflugfelder SC, Pereira I, Cleary T, Rabinowitz S, Atherton SS. Detection of herpes viral genomes in normal and diseased corneal epithelium. Curr Eye Res. 1990;9(6):569-81.

22. Cantin EM, Chen J, McNeill J, Willey DE, Openshaw H. Detection of herpes simplex virus DNA sequences in corneal transplant recipients by polymerase chain reaction assays. Curr Eye Res. 1991;10(Suppl 1):15-21.

23. Laycock KA, Lee SF, Stulting RD, Croen KD, Ostrove JM, Straus SE, Pepose JS. Herpes simplex virus type 1 transcription is not detectable in quiescent human stromal keratitis by in situ hybridization. Inves Ophthalmol Vis Sci. 1993;34(2):285-92

24. Openshaw H, McNeill JI, Lin XH, Niland J, Cantin EM. Herpes simplex virus DNA in normal corneas: persistence without viral shedding from ganglia. J Med Virol. 1995;46(1):75-80

25. Alvarado JA, Underwood JL, Green WR, Wu S, Murphy CG, Hwang DG, et al. Detection of herpes simplex viral DNA in the iridocorneal endothelial syndrome. Arch Ophthalmol. 1994;112(12):1601-9. Comment in: Arch Ophthalmol. 1995; 113(10):1226-8

26. Holbach LM, Font RL, Baehr W, Pittler SJ. HSV antigens and HSV DNA in avascular and vascularized lesions of human herpes simplex keratitis. Curr Eye Res. 1991;10(Suppl):63-8.

27. Farhatullah S, Kaja S, Athmanathan S, Garg P, Reddy SB, Sharma S. Diagnosis of herpes simplex virus-1 keratitis using Giemsa stain, immunofluorescence assay, and polymerase chain reaction assay on corneal scrapings. Br J Ophthalmol. 2004;88(1):142-4.

28. Martínez MJ, Vogel M, Stoppel J, Charlin R, Squella O, Srur M, et al. [Herpetic keratitis: clinical-virological correlation]. Rev Med Chil. 1997;125(6): 659-64. Spanish.

29. Koizumi N, Nishida K, Adachi W, Tei M, Honma Y, Dota A, et al. Detection of herpes simplex virus DNA in atypical epithelial keratitis using polymerase chain reaction. Br J Ophthalmol. 1999;83(8):957-60. 